\title{
AMAMENTAÇÃO EM CRIANÇAS COM SÍNDROME DE DOWN: A PERCEPÇÃO DAS MÃES SOBRE A ATUAÇÃO DOS PROFISSIONAIS DE SAÚDE
}

\author{
BREAST FEEDING IN DOWN'S SYNDROME CHILDREN: \\ MOTHER'S PERCEPTION ABOUT THE PRACTICES OF HEALTH PROFISSIONALS
}

\author{
Suely Teresinha Schmidt Passos de AMORIM ${ }^{1}$ \\ Herivelto MOREIRA ${ }^{2}$ \\ Telma Elisa CARRARO ${ }^{3}$
}

RESUMO

\begin{abstract}
O objetivo deste estudo foi entender a percepção de mães de crianças com Síndrome de Down sobre o aleitamento materno, sua relação com essa prática e a atuação do profissional de saúde nesse contexto. A metodologia utilizada foi a da pesquisa qualitativa. A amostra foi composta por 14 mães de crianças com Síndrome de Down. O instrumento de coleta de dados foi a entrevista semi-estruturada, organizada através de um protocolo que continha questões sobre a percepção das entrevistadas quanto ao aleitamento, seu significado, seus anseios, dificuldades ou facilidades. Os principais resultados revelaram que, além dos aspectos relacionados à criança, o impacto causado pela notícia de um filho deficiente, bem como, a presença ou não de profissionais de saúde capacitados e sensíveis na orientação e apoio à essas mulheres, podem ser fatores inibidores ou facilitadores do processo de lactação.
\end{abstract}

Termos de indexação: aleitamento materno, Síndrome de Down, orientação materna.

\section{ABSTRACT}

The purpose of this study was to understand the perception of mothers of children with Down's Syndrome about breast feeding, their relationship with this practice and the health professional performance in this context. The methodology used was the qualitative one. The sample was composed of forteen (14) mothers of children with Down's Syndrome. The technique used to collect the data was the semi-structured interview. The interview schedule had questions related to mothers' feeling about breast feeding, its meaning, their longings, difficulties or habilities. The main results revealed that, besides the problems

\footnotetext{
(1) Departamento de Nutrição da Universidade Federal do Paraná, Rua Lotário Meisnner, 3400, Jd. Botânico, 80210-170, Curitiba, PR. Fone/Fax (041) 360-4051.

(2) Departamento de Pós-Graduação da Pontifícia Universidade Católica do Paraná

(3) Departamento de Enfermagem da Universidade Federal do Paraná.
} 
related to the child, the impact caused by the news of having a child with deficiency, as well as the presence or not of capable and sensitive health profissionals in the orientations to these mothers, can be factors which contribute to inhibit or to facilitate the lactation process.

Index terms: breast feeding, Down Syndrome, mother guidance.

\section{INTRODUÇÃO}

Embora o aleitamento materno seja um processo biológico, seus modelos de aprendizagem e manifestação são de origem social. Por isso, “ ... para ser bem sucedida nessa prática, a mulher necessita de apoio da sociedade" (Hardy \& Osis, 1991).

Portanto, para que ocorra a amamentação, não basta o funcionamento adequado de glândulas mamárias íntegras, mas de um conjunto de fatores que vão desde o desejo de amamentar, o preparo para a amamentação, e bom estado emocional e psicológico, a sucção pelo bebê de forma a estimular a produção e a ejeção do leite, até o apoio e a orientação segura de um profissional competente.

As vantagens do aleitamento materno, tanto no que se refere ao aspecto nutricional e imunológico, quanto no estabelecimento do vínculo afetivo entre mãe e filho, são fartamente comprovadas na literatura. $\mathrm{O}$ incentivo a sua prática passou a ser enaltecido a partir do momento em que organismos nacionais e internacionais passaram a acreditar que podem ser reduzidas as taxas de morbidade e mortalidade infantil, principalmente nos países em desenvolvimento.

A literatura tão rica na questão do aleitamento materno para crianças em geral, é escassa quando se trata de crianças com Síndrome de Down. É possível que a justificativa para esse fato seja baseada na crença de que o aleitamento dessas crianças é idêntico às demais. Entretanto, devido as características próprias da criança e especialmente pelo estado emocional da mãe por ocasião do nascimento de um filho deficiente, essa prática pode ser prejudicada.

A Síndrome de Down, também conhecida por trissomia do 21, é uma alteração genética caracterizada por um cromossomo extra do par 21 acrescido ao par normal, resultando em alterações físicas e mentais do indivíduo. Lefévre (1988), afirma que “...do ponto de vista da neuropatologia, o dado mais importante é a desaceleração do desenvolvimento do sistema nervoso central. O cérebro é reduzido de volume e peso, especialmente nas zonas do lobo frontal, tronco cerebral e cerebelo".

A Síndrome de Down é conhecida desde a antigüidade e, segundo Hayes \& Batsham (1993), sua prevalência em todas as regiões do mundo, é em média, um em 700 nascidos vivos. De acordo com esses dados, pode-se estimar para o Brasil uma prevalência aproximada de 300 mil pessoas com essa deficiência.

Embora o bebê com Síndrome de Down deva receber aleitamento materno, sua sucçãoé insuficiente devido ao tônus muscular diminuído e, muitas vezes, a própria mãe não tem condições de amamentar devido ao estresse emocional ocasionado pelo impacto da notícia (Cooley \& Graham, 1991).

A notícia do nascimento de uma criança com problemas ao invés do filho idealizado, principalmente quando o profissional de saúde não está preparado para a sua transmissão, pode causar sérios transtornos no equilíbrio emocional da mãe, com repercussões no processo de aleitamento. Segundo Arena (1987), a mairoria dos médicos não está preparada para transmitir a notícia aos pais. No entanto, esses profissionais não são totalmente culpados por isso, pois, durante sua formação acadêmica não foram preparados para situações como essa. Procurando se desvencilhar da difícil tarefa, muitos profissionais informam aos pais de forma rápida, se limitando aos aspectos técnicos ou clínicos, geralmente desatualizados, não considerando os reflexos de sua atitude no estado emocional da mãe, no vínculo mãe/filhoe suas consequiências no processo de lactação.

Segundo Nursing... (1995), a necessidade do aleitamento materno em crianças com Síndrome de Downé considerada particularmente importante devido a hipotonia muscular e a susceptibilidade à infecções respiratórias, além do estabelecimento do vínculo mãe/filho.

Entretanto, devido aos fatores já mencionados, a amamentação nessas crianças nem sempre ocorre naturalmente, e muitas vezes, ela não acontece. $\mathrm{O}$ estímulo e a orientação de sua prática - quando 
realizados - geralmente seguem as políticas estabelecidas pelos órgãos oficiais para o aleitamento materno da população em geral, sem o apoio, dedicação e paciência que o caso requer.

Tendo em vista essas questões, este estudo teve como objetivo entender a percepção de mães de crianças com Síndrome de Down sobre o aleitamento materno, sua relação com essa prática e a atuação do profissional de saúde nesse contexto.

\section{MATERIAL E MÉTODOS}

Este estudo é parte de uma dissertação de Mestrado em Educação que trata da dimensão humana na formação dos profissionais de saúde, especialmente em relação à Síndrome de Down e ao aleitamento materno.

Seu objetivo conduz para uma pesquisa interpretativa, a qual, segundo Moreira (1996), tem como interesse o significado que as pessoas dão aos diversos fenômenos da vida social.

Neste tipo de pesquisa, o fenômeno social concreto é o ponto de partida; valoriza-se o conteúdo da percepção. $\mathrm{O}$ ambiente natural é a fonte direta de dados e o pesquisador o instrumento-chave, preocupado com o processo e não simplesmente com os resultados. Os fenômenos são descritos com os significados fornecidos pelo ambiente e a interpretação dos resultados surge da percepção de um fenômeno no contexto. Privilegia-se a análise dos significados que os sujeitos dão ao fenômeno, os quais, dependem dos pressupostos culturais do meio em que vivem(Triviños, 1992).

Por se preocupar mais com a compreensão abrangente e profunda do grupo social do que com a generalização dos dados, o critério que define a amostra da pesquisa qualitativa não é numérico. A seleção da amostra é baseada na definição do grupo social mais relevante para a pesquisa, ou seja, aquele com atributos que o pesquisador deseja conhecer. $\mathrm{O}$ número da amostra é considerado suficiente quando há reincidência de informações sem deixar de considerar, entretanto, informações ímpares com explicações que devam ser levadas em conta (Minayo, 1993).

A amostra desta pesquisa foi composta por 14 mães de crianças com Síndrome de Down, residentes em Curitiba(PR), cujos filhos deveriam ter no momento da entrevista, menos de 1 a 8 anos completos. Esses dados foram obtidos através da Associação Reviver Down, com sede em Curitiba e possui cadastradas em torno de 350 famílias.

A idade, a condição socioeconômica, a escolaridade e o fato de terem ou não amamentado seus filhos, não foram critérios considerados na amostragem.

A técnica empregada para a coleta de dados foi a entrevista semi-estruturada que obedeceu a um protocolo previamente elaborado. Foram realizadas duas entrevistas com cada mãe. Na primeira, com duração entre 20 e 40 minutos, foram abordados os aspectos gerais, como a experiência em ser mãe de uma criança com Síndrome de Down e o aleitamento materno. Na segunda, foram questionados os aspectos específicos da amamentação, complementando as informações anteriores. Todas as entrevistas foram gravadas, transcritas e como critério de validação, os dados foram checados pelas entrevistadas. Para assegurar o anonimato das entrevistadas e de seus filhos, seus nomes pessoais foram substituídos por nomes bíblicos.

O fato de transcrever e ler várias vezes as entrevistas proporcionou maior familiaridade com o seu conteúdo, permitindo a criação de categorias que emergiram dos próprios dados coletados eque atendiam os objetivos propostos. Essas categorias: o impacto da notícia; dificuldades e facilidades na amamentação; dificuldades não superadas: mães que não conseguiram amamentar; experiência e o significado da amamentação, constituem os resultados deste estudo.

\section{RESULTADOS E DISCUSSÃO}

Todas as mães entrevistadas tentaram amamentar seus filhos, o que vem corroborar o estudo de Oliveira Filho et al. (1986), que evidenciam uma predisposição natural das mães para amamentar.

Verificou-se que a idade das mães, por ocasião do nascimento do filho, variava de 19 a 39 anos. Seis mães têm formação universitária, e a maioria delas não exerce atividade fora de casa.

Houve um grupo de mães que conseguiu amamentar por um período prolongado, algumas sem qualquer dificuldade e outras com problemas iniciais que foram em seguida superados. Para o outro grupo, as dificuldades permaneceram, levando logo a 
complementação ou desmame. E por último, um terceiro grupo, cujas mães por mais que tentassem não conseguiram amamentar seus filhos, ou se o fizeram foi por um período muito_curto, 20 dias no máximo.

Vários fatores contribuíram para a realização ou não do aleitamento. De acordo com os dados dessa pesquisa, a forma como foi transmitida a notícia do nascimento de um filho com Síndrome de Down para a mãe e o impacto desse fato no seu estado emocional, foi um fator importantíssimo para a concretização ou não da amamentação. Esse fato foi decisivo também, na relação da mãe com o profissional de saúde - geralmente o pediatra-e conseqüentemente na orientação e estímulo para o aleitamento. Devido a sua importância no contexto do tema, ela é a primeira categoria a ser interpretada e que foi elaborada a partir das falas das entrevistadas.

\section{A notícia e seu impacto}

Para a família que recebe a notícia do nascimento de uma criança com Síndrome de Down - depois de tantos sonhos e idealizações acerca do nascimento e futuro de seu filho - ouvir que ele não corresponde a todas as suas expectativas, que pelo contrário, é uma criança com limitações no seu desenvolvimento com as quais terá que conviver o resto da vida, é um momento dificílimo.

O relato de Rebeca, caracteriza essa situação:

“... quando eu engravidei do Tiago, foi aquela festança, ele era um nenê assim, extremamente balançado, muito esperado. ...e, ele veio. Foi horrível! Nossa, acho que foi a pior experiência que já tive”.

O desespero dos pais, muitas vezes, é tão grande que é comum nessas situações, segundo Regen et al. (1993) que mães desejem não só a própria morte como a de seu filho chegando inclusive, a verbalizar de que forma o fariam.

Entretanto, esse momento pode ser menos doloroso e superado rapidamente, quando o profissional possui uma conduta adequada, é sensível e sobretudo não destrói todas as expectativas dos pais. Esse tipo de atitude, foi revelada por Ester: “... ela foi uma pediatra muito boa. Ela já explicou que ele ia falar, que ele era uma criança quase perfeita. Então, por isso, ela não assustou a gente, então eu nunca tive aquele medo que ele fosse ser uma criança muito diferente das outras".

Em algumas falas, é possível perceber o carinho para com o profissional que transmitiu a notícia, que soube fazê-lo de forma a não traumatizar os pais.

Borges (1991), argumenta que é preciso descobrir com as pacientes de que forma o saber específico do profissional de saúde poderá ajudá-las. A sensibilidade, a empatia - o colocar-se no lugar de - são pontos que podem facilitar esse momento difícil para os pais, mas sem dúvida, também para o profissional. Com a ajuda desses profissionais, essas mães conseguiram superar dificuldades e amamentar seus filhos.

Para algumas mães a notícia de que o filho nasceu deficiente foi seguida de outra também traumatizante, geralmente, sobre a existência de uma doença associada ou a necessidade de uma intervenção cirúrgica. Além das dúvidas geradas quanto ao desenvolvimento e potencialidades de seu filho, as incertezas quanto ao futuro - próximo ou distante enfim todo o processo de assimilação e aceitação de uma criança deficiente, vem a insegurança quanto a sua sobrevivência, como identificado na fala de Madalena:

"E aí, quando me deram a notícia de que ela era cardíaca, quando me falaram que o problema cardíaco era grave, aí eu desmoronei. Foi o momento que eu desmoronei. Foi mais de uma semana depois da notícia [de que a filha era SD], porque eu não sabia mais como lidar. Tudo o que eu tinha elaborado em termos de possibilidade de organizar a vida, saiu. Fiquei sem chão".

Para Regen et al. (1993), alguns profissionais por não estarem emocionalmente preparados para dar a notícia aos pais, o fazem de "...uma forma destrutiva - como se os pais nada devessem esperar daquela criança em termos de desenvolvimento", aumentando o seu desespero e a sua angústia.

Essa experiência foi revelada por Rute:

"Tinha uma junta médica de 8 pediatras. Aí, eles falaram prá mim que era prá eu pegar ela, que ela era como um trapo, que era prá eu ver que ela era como um trapo, que ela ia ser uma criança que nunca ia andar, que nunca ia falar, que nunca ia pegar nada com a mão. Aí, eu fiquei muito desesperada. Eu cheguei no quarto num 
desespero tão grande. Era enfermaria. Aí, eu olhava, era o $8^{\circ}$ andar, eu olhava lá de cima, eu tinha vontade de me jogar lá de cima, de tanto desespero que me deu”.

É provável que a "junta de oito pediatras" fosse formada pelo professor e seus alunos, residentes ou acadêmicos, já que se tratava de um hospital escola. Verifica-se através do depoimento desta mãe, a repetição de uma prática pedagógica que, de acordo com Hoffmann (1993), influencia a formação de futuros profissionais de forma negativa e destrutiva levando, conseqüentemente, a uma prática médica desumana.

Diante de situações como essa, é fácil compreender o desespero da mãe e a dificuldade em amamentar sua filha. A qualidade da relação profissional-paciente sofre um abalo e qualquer forma de comunicação, especialmente dúvidas que a mãe tenha inclusive sobre o aleitamento, não serão resolvidas.

Regen et al. (1993), evidenciam outro tipo de atitude na transmissão da notícia que é a da omissão, muitas vezes pela falta de coragem do profissional em enfrentar a situação e comunicar o problema aos pais. Foi essa conduta do profissional de saúde que ficou evidente na fala de Isabel “...eu não vi o neném no $1^{\circ}$ dia, nem no $2^{\circ}$. No $3^{\circ}$, é que eu fui ver. Quer dizer, eles ficaram adiando, adiando até trazerem o bebê e me contar. Eu tive que pedir para o pediatra vir, para ver o que estava acontecendo".

No caso acima, foi necessário que a mãe solicitasse a presença do pediatra para que ele viesse lhe comunicar o que estava ocorrendo. A demora em conhecer seu filho gerou expectativas e ansiedade na mãe, o que pode ter contribuído também, para a sua dificuldade em amamentar, pois, como argumenta Issler (1983) "...a ansiedade materna pode determinar o desmame, na medida em que atua sobre o reflexo de ejeção."

De acordo com os depoimentos das mães entrevistadas, o momento da notícia pode ser um fator facilitador ou inibidor do processo da lactação, pois além de ter repercussões na aceitação da criança e no estabelecimento do vínculo mãe/filho, está relacionado com uma orientação segura e estimulante sobre a amamentação ou sua total omissão.

As dificuldades e facilidades encontradas pelas mães, constituíram a segunda categoria deste estudo, elaborada a partir dos dados coletados durante as entrevistas.
Dificuldades e facilidades na amamentação

Sucção insuficiente devido ao tônus muscular diminuído (Cooley \& Graham, 1991), problemas cardíacos ou outras complicações que levam a cirurgias e a internamentos, bem como a condição emocional da mãe - determinada especialmente pelo impacto da notícia - são fatores que podem dificultar ou até impedir o aleitamento materno em crianças com Síndrome de Down.

Das mães que fizeram parte deste estudo, três conseguiram amamentar seus filhos sem qualquer dificuldade, de uma forma expontânea e natural, inclusive por um período de tempo prolongado, como pode ser observado na fala de Raquel: "Quando trouxeram o Lucas, eu o coloquei no seio e ele mamou numa boa. Então, ele não deu problema nesse sentido: dei de mamar e ele mamou na hora ...até 1 ano e 1 mês".

Nesses bebês, a hipotonia parece não ter sido acentuada a ponto de dificultar a sucção, ao contrário, verifica-se pelos discursos das mães que eles sugavam normalmente, sendo apresentadas como crianças saudáveis. É o que revela Salomé: “...desde o início, desde os primeiros dias, do $2^{\circ}$ dia de vida que ele mamou, sempre com aquela força, aquela vontade. Ele sempre mamou muito bem, sugava super bem. Sempre mamou, inclusive até 1 ano". Mais adiante comenta: "Até hoje ele não teve nenhum problema cardíaco, nem de intestino que normalmente as crianças têm. Ele sempre foi muito forte".

Essas mães não questionaram se teriam condições de amamentar ou não. São mães que tinham experiências anteriores bem sucedidas no aleitamento e ignoravam qualquer limitação que a criança com Síndrome de Down poderia ter em relação a amamentação. Raquel deixa isso evidente em sua fala: “... a gente não sabe de nada quando a criança nasce, nada, não sabe da hipotonia, não sabe de nada”.

O fato de não saberem dessas possíveis limitações pode, inclusive, ter contribuído para o sucesso do aleitamento, na medida em que, ficaram isentas de uma preocupação a mais. Chegavam a estranhar a insistência dos profissionais de saúde em saber se a criança estava mamando bem: “... e o meu médico não parava de perguntar: Salomé, mas ele está sugando? E eu não sabia porque era que ele perguntava...". 
Para outras mães a amamentação foi um processo mais difícil de se estabelecer em virtude de problemas relacionados à criança e, algumas vezes também, a elas próprias. Porém, a vontade, o querer amamentar fez com que superassem essas dificuldades. Algumas delas conseguiram amamentar normalmente, decorridos alguns dias após o nascimento da criança. Ester caracteriza bem essa situação: “... foi muito difícil para mamar porque eles não têm aquela força que os outros têm. Depois até ele aprender, tinha que tirar e por na chuquinha e dar prá ele. Eu nunca tive bico do peito. Então tinha que fazer com o aparelhinho [bico de silicone]. Então, assim, ele foi mamando até aprender bem. Depois que ele aprendeu, aí foi embora".

O espaço de tempo logo após o nascimento do bebê e até que a amamentação se concretizasse, o que durou aproximadamente uma semana, exigiu paciência e disponibilidade das mães, como pôde ser observado em suas falas, seja pelo tempo dispensado a cada mamada, seja pela necessidade de usar de artifícios como o bico de silicone - ou de esgotar o leite o que, de um modo geral, se constitui num processo doloroso, tanto física quanto emocionalmente. Como evidenciam Bom Ângelo \& Goldstein (1996), “o processo de amamentação envolve um compromisso de entrega e dedicação. A mulher enfrenta uma fase de renúncias temporárias, perdendo o comando de seus próprios horários, colocando o contato a seu filho como meta prioritária nesse período".

Anna, teve seus 2 filhos com Síndrome de Down e apesar de alguns problemas iniciais relacionados com a dificuldade de sucção e mamilo plano, amamentou ambos por um período superior a 6 meses. Seu primeiro filho além da Síndrome de Down, apresentava um quadro de leucemia e por isso, sua segunda gravidez não foi planejada e nem desejada. Entretanto, apesar de todos esses problemas, associados a notícia do nascimento de outra criança sindrômica, apresentando ainda refluxo esofágico, ela conseguiu amamentar. Para essa mulher, assim como para outras que fizeram parte desse estudo, a amamentação é algo naturale inquestionável. Terum filho significa também amamentá-lo. E Anna revela isso ao afirmar: "Toda vida desejei amamentar meus filhos porque eu sempre fui daquela opinião de que o leite materno era bem melhor..." Como salienta Ayres Neto (1986), “... muitas mulheres conseguem amamentar, apesar de toda sorte de dificuldades e pressões desfavoráveis".
Outras mães que amamentaram seus filhos encontraram dificuldades semelhantes às anteriores mas, não conseguiram superá-las e depois de algum tempo viram que seus bebês não aumentavam de peso, tendo que optar pela complementação. Rebeca é uma delas. Vejamos seu depoimento: "Atéo $3^{\circ}$ mês eu tentei só com o aleitamento materno, mas devido a esse problema [refluxo e hipotonia], ele não estava tendo alimentação adequada e estava perdendo peso, perdendo peso. Então trocou, a amamentação ficou como maneira complementar...".

Eva teve dificuldades semelhantes, com consequiências para o crescimento de seu bebê que necessitava do aumento de peso para ser submetido a cirurgia cardíaca.

“...ela tem problema cardíaco e só no seio ela estava fazendo muita força para sugar e não estava ganhando peso. Por isso, o pediatra achou melhor introduzir a mamadeira junto. Mas, daí, eu achei melhor ficar só no seio, porque eu falei, ela vai acabar largando cedo do seio. Então, eu, por conta própria, fui tirando da mamadeira e deixando só no seio. Daí, nesse mês - acho que foi no $2^{\circ}$ mês - que ela ficou só no seio, ela engordou só 30 gramas".

Através de depoimentos como esse é possível perceber a resistência das mães em optar pela complementação, preocupadas com o fato do bebê dar preferência a mamadeira. Esta é uma das informações veiculadas pela mídia e transmitida também, em todas as orientações sobre aleitamento materno: as mães devem evitar o uso de mamadeiras e até chupetas para que o bebê permaneça mamando em seu seio. Informações como essa, recomendáveis e aplicáveis a maioria da população, podem se tornar prejudiciais em casos específicos, em que a criança devido a uma deficiência ou doença - ou ambos -, não consegue obter o leite necessário para o seu crescimento e desenvolvimento. Daí, a importância da atuação de um profissional suficientemente sensível e humano para perceber a angústia da mãe, tranqüilizála e orientá-la sobre a melhor alimentação para o seu filho.

Ao orientar a gestante ou a puérpera, a competência técnica e a segurança dos profissionais de saúde, bem como a qualidade da relação interpessoal é fundamental para o sucesso do aleitamento materno (Bom Ângelo \& Golsdtein, 
1996). Isso pode ser constatado na fala das mães que conseguiram amamentar sem dificuldades ou que conseguiram superá-las com a ajuda dos profissionais que as assistiam, como no caso de Raquel: “... o pediatra me incentivava no aleitamento materno. Toda vida me incentivou".

Alguns profissionais, além do estímulo, permaneciam atentos às dificuldades que as mães encontravam, orientando-as e sobretudo apoiando-as no processo da amamentação. É o caso da médica que atendeu Ester, "Ela (a pediatra) ia lá e colocava o Pedro em meu seio prá ele sugar. Ficava ali esperando até ele mamar, ela não ia embora, não. Enquanto ele não mamava um pouquinho, ela não ia. Ela me ajudou muito, me ajudava muito, tudo ela ajudou. Ela é muito boa”.

Se para as mães de crianças normais, a atuação dos profissionais de saúde é importante para o estabelecimento do aleitamento, para mães de crianças com Síndrome de Down as evidências mostram que a participação, o apoio e a orientação são imprescindíveis, uma vez que, muitas delas não amamentam porque não conseguem superar sozinhas determinados problemas, como por exemplo, a dificuldade de sucção de seu filho. Dessa constatação surgiu outra categoria, elaborada a partir dos relatos de mulheres que não conseguiram amamentar devido a dificuldades não superadas.

Dificuldades não superadas; mães que não conseguiram amamentar

Embora todas tivessem intenção e vontade de amamentar seus filhos, cinco mães por mais que tentassem não conseguiram fazê-lo. "...quando eu trouxe o Mateus do hospital, eu estava cheia de leite, só que ele não sugava. Eu não sabia o que fazer".

A angústia de algumas mães ao insistir no aleitamento e verificar ao final, que seu filho não tinha condições de ser amamentado, fica evidente em relatos, como o de Débora, que aos 19 anos teve sua primeira filha com Síndrome de Down: "Não mamou. Eu insisti, nossa, eu cheguei a ficar até assim meio desesperada, porque eu queria amamentar, eu tinha leite, estava até empedrando, tinha que estar tirando e fiz isso durante uma semana, só esgotando prá dar prá ela e pondo ela no seio e, não teve jeito".

Um dos principais fatores que impediu a amamentação, segundo esses relatos, foi a insuficiente sucção ao seio pelo bebê, pois de acordo com a publicação da Organización... (1989) "a sucção vigorosa é um estímulo potente para a secreção da prolactina e da ocitocina que, respectivamente, iniciam a secreção láctea e estimulam o reflexo da descida do leite...” Rute confirma esse fato em sua fala: “... quando eu saí do hospital, ela ficou porque não tinha muito peso. Ficou também tomando banho de luz. Aí, eu ia lá prá amamentar. Só que ela não, ela até que pegava o seio, mas não tinha força para sugar".

Uma das crianças apresentou problema cardíaco grave, não conseguindo sugar o seio materno o que corrobora a argumentação de Mathias (1986), de que as cardiopatias graves, principalmente as que levam a cianose, constituem um obstáculo ao aleitamento natural. Madalena, revela as dificuldades que enfrentou na tentativa de amamentar sua filha: “...a questão da amamentação era problemática porque ela não conseguia sugar e aí, duas vezes fez apnéia no meu colo. Ela não conseguia coordenar a respiração e a sucção".

Embora sua filha não tivesse apresentado nenhum dos problemas anteriores, Sarah relatou que ficou emocionalmente abalada com o impacto da notícia, e esta, possivelmente, foi a causa de sua hipogalactia.

...ela estava desde $6^{a}$ feira sem se alimentar, não aceitava mamadeira, cházinho, nada. Então, eu achei interessante que, eu botei ela no colo, ela sugou no peito, no domingo isso, dois dias depois que ela tinha nascido. Mas, por muito pouco tempo que ela mamou. Acho que não chegou a 20 dias, daí secou o meu leite, não tive mais e foi para a mamadeira. Eu não sei se foi por causa desse estresse todo com o nascimento dela, que o leite secou. Só pode ter sido, porque do теи $1^{o}$ filho, eu tive, durante 1 ano, eu tive leite. Ela, com 20 dias, eu não tinha mais leite.

Segundo Bom Ângelo \& Goldstein (1996), “os mecanismos responsáveis pela produção e liberação de leite são muito suscetíveis aos efeitos do cansaço físico, bem como aos fatores emocionais, que podem gerar tensão e ansiedade". Dessa forma, e ainda de acordo com essas autoras, as mensagens transmitidas pelos profissionais de saúde, sua atitude em relação as puérperas, podem ser fatores facilitadores ou inibidores da lactação. 
Nas falas das mães que conseguiram amamentar apesar das dificuldades, ficou constatado que um dos fatores que contribuiu para que isso acontecesse foi a orientação e o estímulo recebido dos profissionais de saúde. É possível verificar também que, para a maioria das mães que não conseguiu amamentar, a falta dessa orientação e apoio, contribuiu para que a amamentação não ocorresse. É o caso de Isabel: “... no hospital não tinha ninguém que te ajudasse, que te orientasse. Mas, talvez se eu tivesse insistido mais, ou mesmo um pediatra tivesse me orientado...".

O abandono, a falta de orientação e apoio que essas mães sentiram foi identificado também no estudo de Araújo (1991), surge na fala de Rute e coloca em dúvida o papel(não) desempenhadopelos profissionais de saúde em relação a prática do aleitamento: “...eu não tinha experiência nenhuma, não tinha ninguém que me ajudasse. Aí eu fui me desanimando com aquilo. Eu queria muito ter amamentado, só que eu não tive sorte, não deu não. Às vezes assim, se tivesse alguém que me ajudasse na hora ali, podia até ter dado certo".

Apesar de toda intensa campanha veiculada pela imprensa, parece que o descaso, a indiferença com um tema tão importante, continua sem merecer a atenção de muitos profissionais e instituições de saúde. Esse desinteresse foi demonstradonoestudo de Oliveira \& Spring (1984), no início do Programa Nacional de Incentivo ao Aleitamento Materno (PNIAM) e em período recente por Garcia-Montrone \& Rose (1996). Essa atitude, encontrada em relação a uma população normal, pode ser agravada quando se trata de uma clientela que necessita de maior atenção, sensibilidade e conhecimento técnico, qualidades que, até por defeito na formação, estão ausentes em muitos profissionais.

Por outro lado, a pressão e a insistência demasiada para que a mãe amamente quando não consegue, só faz aumentar sua sensação de culpa. Muitas vezes, os profissionais de saúde, imbuídos das melhores intenções e porque foram instruídos e motivados para a prática do aleitamento materno, não admitem que uma mãe tenha motivos para não amamentar. Esses motivos podem estar ligados a dificuldades apresentadas pela criança ou como consequiência de seu estado emocional. Odepoimento de Madalena demonstra essa situação: “...eи ехрliquei prá ele: doutor, ela não suga, eu não tenho leite para estimular, não vem mais do que 10 ou $15 \mathrm{ml}$. Ele: Não, mãe, você tem que fazer. Eu disse: tudo bem, eи estou tentando, mas ela vai morrer de fome desse jeito. Ele foi taxativo: você tem que fazer".

Esta é uma situação em que a empatia, a sensibilidade para conhecer e compreender todas as dificuldades que a mulher está enfrentando naquele momento, é fundamental para a orientação sobre a alimentação de seu filho. Uma das funções do profissional de saúde é manter a mãe bem informada sobre as vantagens da amamentação, assim como apoiá-la e orientá-la sobre a melhor conduta a seguir. Entretanto, a insistência demasiada para o aleitamento em mulheres contrárias a amamentação ou que não tem condições de amamentar, provoca sentimentos de culpa e angústia materna; por isso, os profissionais devem orientar e incentivar, mas jamais decidir pela mãe (Carvalho, 1985; Bom Ângelo \& Goldstein, 1996)

Todas as mães que fizeram parte desse estudo desejaram amamentar seus filhos. Para algumas esse desejo foi concretizado e o significado desse fenômeno teve uma conotação muito diversa do que para aquelas que não conseguiram. Os relatos das mães sobre a experiência e os sentimentos que envolveram a realização ou não da amamentação, forneceram dados para a elaboração da quarta categoria deste estudo.

Experiência, significado da amamentação; sentimento em não conseguir amamentar

Para as mães que conseguiram amamentar, independentemente das dificuldades encontradas, essa experiência é sentida como gratificante e prazerosa. É o que nos relata Marta "...eu tinha muito prazer, muita felicidade em amamentar".

A relação mãe/filho, o vínculo tão enfatizado na literatura, também é mencionado nos discursos das mulheres, como Maria: “...me realizei como mãe, porque eu tinha prazer. Se ser mãe realizada é amamentar, então, com ela eu consegui me realizar", ou Rebeca: "Ah, é uma ligação muito forte, é aquele instinto maternal realizado. É aquela proteção, carinho, éaquela ligação, aquele elo muito forte, muito importante".

Arantes (1995), menciona em seu estudo que "as colocações sobre a amamentação como experiência boa vêm sempre em primeiro lugar”, somente depois na continuidade do relatoé que as mulheres expressam as dificuldades encontradas no aleitamento. Isso se 
deve, segundo a autora, ao fato de que, socialmente, amamentar é considerado um ato de amor e a mãe que não o faz é vista como 'desnaturada' e 'culpada de não amar o seu filho’.

Também neste estudo algumas mulheres colocaram a amamentação como uma experiência difícil, considerando as limitações características da criança com Síndrome de Down. Rebeca, além da satisfação em amamentar, relata suas dificuldades: "Ah, meu Deus, eram 24 horas do dia no seio, porque ele tinha que arrotar e quando ele arrotava, ele já vomitava".

O lado emocional, todo o processo de aceitação da criança com Síndrome de Down, envolve muito sofrimento e tem consequiências na amamentação. É ainda, Rebeca quem faz um depoimento contundente sobre essa questão: “.. a minha parte emocional estava muito abalada. Eu, mulher, estrutura, apesar de eu não querer reconhecer, hoje eu sei que eu estava muito abalada, que eu não tinha tudo aquilo para dar para o Tiago. Então, isso afetou muito, sabe, a minha parte emocional".

O cansaço físico, o desconforto também fazem parte do aleitamento e é relatado por Sarah: “... era uma coisa tão chata amamentar, porque doía muito, o leite empedrava, aquela dor no seio, era muito desconfortável para mim".

Para as mães que não conseguiram amamentar, a tentativa em fazê-lo, a experiência em esgotar o leite através da sugadeira manual, geralmente se constituiu em um processo desgastante e doloroso, como percebese nas falas de Débora “...mas ainda assim, insisti por duas semanas, até que não agüentava mais, meu seio ficou todo machucado de estar tirando o leite e esgotando...” e de Madalena: “...eu fazia aquelas massagens embaixo do chuveiro, tomava chá, que eu não gostava, algumas coisas assim, fui tentando fazer. A hora que estava doendo muito, eu fazia aquele tratamento natural com a casca da banana para diminuir a dor, o ferimento e tudo o mais, causado pela própria sugadeira".

A expressão manual do leite é recomendada sempre que a produção de leite é maior do que a demanda, ou seja, quando o bebê por qualquer dificuldade não suga o suficiente para esgotar o leite das mamas. Pode ser feita com ou sem a utilização de instrumentos. A expressão manual sem o uso de qualquer aparelho, apenas com técnica adequada, é a mais recomendada por ser menos agressiva e incômoda para a mãe. Entretanto, em situações de ingurgitamento ou quando as mamas estão doloridas, é necessário a retirada do leite com bombas de sucção ou esgotadeiras elétricas, estas últimas, de uso hospitalar. A desvantagem do uso de instrumentos manuais - bombas de sucção -, é que geralmente são ineficazes, podendo aumentar a dor e a irritação nos seios e mamilos (Campestrini, 1983; King, 1991).

A equipe de saúde deve estar apta a orientar a mãe sobre a técnica correta de extração do leite, evitando sofrimentos desnecessários, sempre que possível. Arantes (1995), chama a atenção dos profissionais de saúde que incentivam o aleitamento materno para estarem atentos ao sofrimento, ao cansaço, enfim, serem receptivos às dificuldades relatadas pelas mulheres ao amamentar.

Não conseguir amamentar pode significar para algumas mães, sentimentos de frustração, culpa e impotência. Para Madalena, o esforço e a cobrança da equipe de saúde foi tão grande, que ela se sentiu pressionada e impotente por não conseguir realizar o que se esperava dela: "Eu me senti extremamente frustrada. Por um lado frustrada, por outro lado cobrada, tanto por médicos, como pela sociedade, por todo mundo".

Isabel, que não se esforçou muito e não teve apoio para isso, questiona a sua decisão com um velado sentimento de culpa: "Fico pensando que eu não me esforcei muito. Eu vi que ele não conseguia sugar já acabei dando a mamadeira. Eu fico pensando até hoje: será que não foi mais fácil para mim, que acabei deixando, não insistindo muito?"

Nas duas situações os sentimentos poderiam ter sido diferentes: devido as condições de saúde da criança e o estado emocional da mãe, Madalena, certamente não conseguiria amamentar. A insistência e a pressão para que o fizesse, só serviram para aumentar seus sentimentos de culpa e frustração. Quanto a Isabel, provavelmente teria amamentado se tivesse apoio e orientação adequada.

Para Sarah, prevalece a dor, o cansaço, o estado emocional ao amamentar, por isso, relata que o fato de não conseguir levar adiante a lactação, não lhe causou maiores problemas. “...psicologicamente não me afetou muito. Eu só achava que, por ela ter esse problema, deveria termamado mais tempo, sónesse sentido. Porque ah, era uma coisa tão chata amamentar, porque doía muito...”. 
Em outro momento Sarah revela o quão difícil foi aceitar o nascimento de sua filha com Síndrome de Down, a desestruturação emocional, as mudanças em sua vida profissional, as preocupações com o outro filho, a casa, etc., o que, com certeza, teve reflexos na amamentação.

Ao discorrer sobre os aspectos desagradáveis da amamentação e todas as implicações que ela acarreta na vida da mulher, Arantes (1995) chama a atenção dos profissionais de saúde para considerarem a realidade da experiência de amamentar, não imaginar apenas o ideal, mas sobretudo contemplar o real, que é "constituído também de momentos negativos."

E tratando-se de mães de crianças com Síndrome de Down, a disponibilidade, o estar atento as suas angústias e incertezas, o saber ouvir e, sobretudo, decidir com ela sobre a melhor conduta em relação à alimentação de seu filho, são aspectos que devem ser considerados pelo profissional de saúde que se propõe a atender essa clientela.

\section{CONCLUSÃO}

$\mathrm{Na}$ fala das 14 mães que fizeram parte deste estudo, através de categorias elaboradas a partir das informações por elas fornecidas, ficou evidente que a notícia do nascimento de um filho com Síndrome de Down tem repercussões importantes sobre o processo de aleitamento, por implicar na aceitação e no vínculo mãe/filho. Algumas mães não encontraram qualquer dificuldade para amamentar, sendo que, alguns fatores contribuíram para isso: essas mães tinham experiência anterior bem sucedida de aleitamento e desconheciam qualquer limitação que a criança com Síndrome de Down pudesse ter para sugar. Outras mães conseguiram amamentar superando dificuldades delas próprias e de seus filhos, enquanto que um terceiro grupo enfrentou dificuldades semelhantes ou mais graves e não conseguiu superá-las. Um dos fatores que diferenciou esses dois últimos grupos, foi a presença ou ausência de profissionais sensíveis e competentes na orientação e apoio a essas mulheres, por ocasião do nascimento de seu filho com a Síndrome e durante o processo de lactação. Para as mães que conseguiram amamentar, essa experiência se constituiu em momentos de satisfação, prazer e um profundo vínculo com seu filho. Aquelas que nãotiveram sucesso no aleitamento, relatam sentimentos de impotência, frustração e por vezes, culpa.

Acreditamos que a maioria das mães consegue amamentar seus filhos com Síndrome de Down, para quem essa prática é de fundamental importância. Existem situações entretanto, com sérios obstáculos a realização do aleitamento materno e os profissionais devem estar preparados para identificar esses casos e orientar a mãe sobre a melhor conduta a ser seguida.

$\mathrm{Na}$ riqueza dos depoimentos das mães entrevistadas, fica evidente a necessidade da formação de profissionais humanos, com sensibilidade para entender o sofrimento e a frustração que envolvem o nascimento de um bebê com deficiência, e com capacidade e competência para agir de forma adequada, tanto na transmissão dessa notícia como na orientação e apoio no momento da lactação. Espera-se que os cursos de graduação e os profissionais já atuantes saibam fazer uso dessas falas para ampliar seus horizontes de ensino e aprendizagem.

\section{REFERÊNCIAS BIBLIOGRÁFICAS}

ARANTES, C.I.S. Amamentação: visão das mulheres que amamentam. Jornal de Pediatria, Rio de Janeiro, v.71, n.4,p.195-202, 1995.

ARAÚJO, L.D.S. Querer/poder amamentar. Uma questão de representação? Florianópolis, 1991. Dissertação (Mestrado em Enfermagem) - Centro de Ciências da Saúde da Universidade Federal de Santa Catarina, 1991.

ARENA, J.F.P. Síndrome de Down. Pediatria Moderna, São Paulo, v.22, n.2, p.39-42, 1987.

AYRES NETO, C. Aspectos emocionais do aleitamento. Femina, Rio de Janeiro, v.14, n.10, p.934-936, 1986.

BOM ÂNGELO, M.L.; GOLDSTEIN, R.A. Aspectos emocionais presentes na amamentação. Pediatria Moderna, São Paulo, v. 32, n. 2, p. 182-188, abr., 1996.

BORGES, S.M.N. Propostas para uma relação: profissionais de saúde e mulheres. Cadernos de Saúde Pública, Rio de Janeiro, v.7, n.2, p.284-289, 1991.

CAMPESTRINI, S. Alojamento conjunto e incentivo à amamentação. Curitiba: Educa, 1983.97p.

CARVALHO, M. Obstáculos ao aleitamento materno: fatos e mitos. Jornal de Pediatria, Rio de Janeiro, v.50, n.4,p.403-414, 1985.

COOLEY, W.C., GRAHAM, J.M. Common syndromes and management issues for primary care physicians - 
Down Syndrome - an update rewiew for the primary pediatrician. Clinical Pediatrics, Philadelphia, v.30, n.4,p. 233-253, 1991.

GARCIA-MONTRONE, V., ROSE, J.C. Uma experiência educacional de incentivo ao aleitamento materno e estimulação do bebê, para mães de nível sócio-econômico baixo: um estudo preliminar. Cadernos de Saúde Pública, Rio de Janeiro, v.12, n.1, p.61-68, 1996.

HAYES, A., BATSHAM, M.L. Down Syndrome. Pediatric Clinics of North America, Philadelphia, v.40, n.3, p.523-535, 1993 .

HARDY, E.E., OSIS, M.J.D. Mulher, trabalho $e$ amamentação: legislação e prática. Campinas : UNICAMP, 1991.113p.

HOFFMANN, L. A morte na infância e sua representação para o médico: reflexões sobre a prática pediátrica em diferentes contextos. Cadernos de Saúde Pública, Rio de Janeiro, v.9, n.3, p.364-374, 1993.

ISSLER, H. Aleitamento materno: ansiedade $v s$. lactação. Pediatria, São Paulo, v.18, n.5, p.98-99, 1983.

KING, F.S. Como ajudar as mães a amamentar. Londrina:UEL, 1991.173p.

LEFÉVRE, B.H. Mongolismo: orientação para as famílias. 2.ed. São Paulo: Almed, 1988. 188p

MATHIAS, L. Contra-indicações e obstáculos ao aleitamento materno. Femina, Rio de Janeiro, v.14, n.10,p.927-929, 1986.

MINAYO, M.C.S. $O$ desafio do conhecimento: pesquisa qualitativa em saúde. 2.ed. São Paulo: Hucitec/Abrasco, 1993.269p.
MOREIRA, H. Pesquisa educacional: reflexões sobre os paradigmas da pesquisa. In: FINGER, A. Educação: caminhos e perspectivas. Curitiba: Champagnat, 1996. p.19-42.

NURSIN MOTHER'S ASSOCIATION OF AUSTRÁLIA. Breastfeeeding a baby with Down's Syndrome. Http://www.vicnet.au/vicnet/nmaa/downsynd.htm.

OLIVEIRA, Y., SPRING, P.M. Pesquisa do programa de incentivo ao aleitamento materno. $2^{\mathrm{a}}$ parte: entrevista com profissionais de saúde e centros de saúde. Jornal de Pediatria, Rio de Janeiro, v.57, n.1, p.93-96, 1984.

OLIVEIRA FILHO, A.P., SILVA, C.J.V., DIAS, T.R. Influência da orientação pré e perinatal sobre o aleitamento materno: estudo com 100 puérperas da maternidade do Hospital da Aeronáutica de Belém (HABE). Jornal de Pediatria, Rio de Janeiro, v.60, n.1/2,p.21-24, 1986.

ORGANIZAÇÃO MUNDIAL DA SAÚDE. Proteção, promoção e apoio ao aleitamento materno: o papel especial dos serviços materno-infantis. Uma declaração conjunta OMS/UNICEF. Genebra, 1989.32p.

REGEN, M., ARDORE, M., HOFFMANN, V.M.B. Mãese filhos especiais: relato de experiência com grupos de mães de crianças com deficiência. Brasília : MBES/ CORDE, 1993.137p.

TRIVINÕS, A.N.S. Introdução à pesquisa em ciências sociais: a pesquisa qualitativa em educação. São Paulo: Atlas, 1992.175p.

Recebido para publicação em 16 de junho e aceito em 18 de agosto de 1998. 